\title{
Deviant Leisure Explores a Radical Criminological Framework to Examine Neo-Liberal Capitalism. Can Deviant Leisure Be Revisioned by Feminism to Include the Emerging 'Other'?
}

\author{
Maive Jackson Collett ${ }^{1}$
}

${ }^{1} \mathrm{PhD}$ student with Flinders University, Australia

Correspondence: Maive Jackson Collett, PhD student with Flinders University, Australia.

Email: mjacksoncollett@gmail.com

Doi: $10.23918 /$ ijsses.v7i3p103

Deviant Leisure is a radical departure from criminology. Finding its home with the ultra-realists it uses concepts from Lacan and Zizek as building blocks to support this revisioning. It is uplifted and improved by a merger with feminism. Social harm is a key concept in Deviant Leisure. It has the potential to transform policy making. Employing a post-disciplinary space, this article combines Deviant Leisure, feminist, and mental health perspectives. It explores the inherent criminological capacities of capitalism. The research deploys the genre of a Creative PhD which reframes the 70s and extends its theorization through a crime novel as an artefact.

Keywords: Deviant Leisure, Neoliberal Capitalism, Creative PhD, Feminism, Social Harm, Mental Health Issues

\section{Introduction}

This article activates a post-disciplinary space. It combines a critical analysis of Deviant Leisure theory. The theorization involves revisioning Deviant Leisure with a feminist lens. The feminist lens can make a significant contribution to Deviant Leisure in a reciprocal exchange. The emerging view is one of observing an 'othering' of women in Deviant Leisure. In addition, the othering of those who have mental health issues is layered into the critique. The article takes the shape of a helical sphere. The helix appears to repeat what has been said before. It does so to allow the reader to reconnect with previously expressed views, pause and reflect. Following reflection then step again into another expansion building a layering effect of knowledge and supporting the reader in a reflective and literary process with the words and the reader.

Deviant Leisure ${ }^{1}$ disturbs the notion that neo-liberalism is beneficial to an individual and an economy and configures questions around social harm. This article enters this dissonance and disturbance and extends it further to examine social harm and women, and social harm and the mentally ill, within a specific and situated context of the 1970s. The significant contribution to knowledge comes from using a developed theoretical framework, Deviant Leisure, critiquing from the standpoint of feminism and neurodiversity then reframing that into the contextual lens of the 1970s in Kings Cross Sydney, a unique built environment.

${ }^{1}$ Deviant Leisure is used as a proper noun throughout. It is a paradigm within the Discipline of Criminology. 
This study is a critical analysis of the 1970s using a current theorization emerging through criminology. The theory employed resonates from the phrase Deviant Leisure, which has emerged from the radical revisioning of the ultra-realist left criminologists. The ultra-realists inverted classical and critical criminology where the focus of criminology sat with the individual, who committed the 'crime'. As Tara Brabazon observes in a podcast, the ultra-realists created a lens which invokes the 'criminological capacities of capitalism' (Brabazon, 2020). The resultant crime novel which is the artefact of this Creative $\mathrm{PhD}^{2}$ (Brabazon, Lyndall-Knight \& Hills, 2020) looks at the novel and its characters from a Deviant Leisure perspective. Instead of simply asking why the characters commit a crime, there is an attempt to look at 'grand' themes. Capitalism and neo-liberalism and the embedded notions the wedded notions of individualism. These are issues we see play out nightly on our television screens. This research subverts the dominant paradigm through its theoretical palette and its creative fiction and the interplay between them.

\section{Social Harm and Zemiology}

Social harm is one of the most potentially potent and transformative concepts currently available to the social sciences (Raymen 2019a, p. 133).

Zemiology encompasses the study of harm in its multiple forms. One of its current focuses is on policy making. Policy making however keeps the focus on the individual as the only actor capable of making a difference. The bigger picture is to move away from the individual to see policy making as inherently limited because neo-liberalism does not change. Capitalism does not change. Changes to policy making keep us looking incorrectly at the medium picture. Not unlike Goldilocks and the three bears looking at the size of chairs is a mis-focus. Revisioning the fairy tale. Moving out of the genre of fairy tales is the only focus that will bring enduring change. Thomas Raymen and Oliver Smith subvert the model of individual focus on risk. The ultra-realists first radically revisioned the Discipline of Criminology using the complex theoretical positions of Lacan and Zizek to understand how systemic social harm becomes embodied in the individual (Winlow 2019; Winlow \& Hall 2013). Deviant Leisure theorists Thomas Raymen and Oliver Smith extend the ultra-realists arguing that neo-liberalism and neo-liberalist capitalism combine and conflate to create social harm.

There are many terms which collude and interplay to inhabit the space of zemiology. This is evidenced in Winlow and Hall's text Rethinking social exclusion: the end of the social? Published in 2013 this academic discussion purposes an interrogation of the concepts that are needed to take in the depth and breadth of what zemiology can offer. As a group of scholars there seems to be a strong desire to define zemiology. Kotze discusses the seminal text of Hillyard (Hillyard et al., 2004) in delineating the relationship between crime and harm (Kotze, 2018). The foundation of the word zemia in Greek meaning harm is noted by Kotze who considers the question of whether to discuss criminology or zemiology and answers 'yes please'. Kotze prefers the field of criminology and argues not to spend valuable time discussing definitions but to proceed using the best of both. It is a common-sense approach but not one that takes examines the implications of a definition and the consequences of the definition either to public policy making or to the

${ }^{2}$ The Creative $\mathrm{PhD}$ is a genre term for a PhD examined by exegesis and artefact - to include artworks, performance and the novel, see Brabazon, Lyndall-Knight \& Hills 2020. 
theorizations on the cause of social harm. Thomas Raymen delves into the subtleties of the term zemia and the implications of its' origins in Chapter One of a codex titled The Assumption of Harmlessness (Raymen, 2020) which like Winlow and Hall (2013) will have a glossary when completed. The glossaries are needed because many of the discussions are predicated on familiarity with multiple definitions which undergird Deviant Leisure. To return to the definition of zemiology.

The word 'zemia' derives from a time and place where ethics and the common good were of concern (Raymen, 2020). However, 'ethical' Greek society was underpinned by slavery, so perhaps this reference can be critiqued. Raymen is substantiating a body of work. Yet there is almost twenty years of scholarly discourse on zemiology. It exists already. Why continue to argue as if it doesn't have roots - Greek in fact. The search is for credibility. Rigorous, robust, empirical and theoretical research enables Raymen to make solid claims which consequently require the reader to consider change. In that zemiology and social harm align with a call. Nay, a cry for change.

The applicability of social harm is wider, deeper, further. The broader definition of zemia is of social harm, of understanding punishment and knowing it is incorporated into the essence of the word (Raymen, 2020). One punishment on the social plane is stigma (Goffman, 1963). If a human being is not in the middle of society, doing the things that expected of us, then they are outside the middle, often discriminated against, and stigmatised for being who they are. This is one of the most virulent forms of social harm on the planet. 'Neuro diversity' identifies a group who suffer from mental health issues. Suffering from mental health issues places a human being outside the norm, deviant.

The sentient being is rejected. Individual suffering might begin on the outside, the person, the being is rejected. Their clothes don't match, it is obvious they are poor as in poverty, sick, mentally ill, vulnerable. Something, either definable or indefinable is wrong with them. Could be the look in their eyes. How do we know they are somehow 'wrong'? The inner radar responds unconsciously. The inner radar comes from a deep need to belong to the herd, to belong. Yet the group and the individual are a binary opposition in this instance.

In the name of the moral superiority of the capitalist system we produce millions of broken identities and self-concepts, devalue skills, competences and biographies, terminate careers and destroy the hopes and expectations stimulated in the first place (Ruggiero, 2003, p. 41 in Musur, 2012).

Harm - zemiology - as subset of criminology intersects with the individual and individual harm. This study begins with a broader look at harm and its place in criminology. The research question asks how is mental health portrayed in - media - the novel? The term media is deployed more by what is omitted than included. Omitted is newspapers, television, film, and channels of media such as Facebook and others. Media is used here to focus on the novel. This work is a creative PhD and as a rising genre in doctoral studies it must defend itself and argue for funding. The challenge is to sustain the best of what currently known but to change what is fundamentally and morally unsustainable. The premise of the word 'known' is inherently static, such as status quo and as such can be derided simply for its existence. Yet the new will always need to prove its value. 
The theoretical underpinnings of the research start with zemiology. Broadly it is a bold rewrite of a narrow view of why people commit crime. The essence of criminology was a simple belief in the rational actor who has a clear choice made from his own internal empiricist view that there is a choice and that the actor is free to choose it. This resembles asking someone starving in the Irish potato famine would they feed their family with this loaf of bread although they would have to steal it first, or would they leave it where it was in a grand house to be thrown out for scraps and pigs. What is legal is a construct of society and here we must crack the wound wide-open. How the choice is made may be rational or not and is potentially bound to ideas of individualism.

About the individual - subjectivity - harm theory argues that neo-capitalism and its children neo-liberalism and atomised individualism have roles to play in the complexity known as life, perhaps known as late modernity. Winlow and Hall proffer a complex explanation which relies on the underpinning theories of Zizek and Lacan to understand subjectivity. Extending high theory still further Raymen and Smith (2019) use harm theory to question how neo-liberalism and individualism combine to allow us to harm ourselves for pleasure. The concept of jouissance here is essential as Lacan intended here to go further than pleasure to that extreme pleasure which may inherently cause pain (Lacan 2008, in Winlow \& Hall 2013, p. 176).

The relationship of Deviant Leisure and ultra-realism is complex. Deviant Leisure finds its home within ultra-realism and many concepts are crucial to both theorizations. Perhaps the generational gap between Raymen and Smith and Hall and the ultra-realists is an issue. Perhaps poverty and class are a significant focus of the ultra-realists which is a function of closer proximity to the 1970s proximity to a more popular Marxism. The generational difference changes the perspective and focus on what is important. Deviant Leisure theorists are more concerned with the contemporary concerns of criminology but also a more cultural interpretation which critiques neo-liberalism and capitalism from a different perspective. Raymen and Smith are part of the contemporary leisure scene whereas the ultra-realists come from a closer connection to 'purer Marxism'. Where many might construe Marxism to be debunked in some respects. It is also a taboo idea. It is out of flavour and favour in universities and something to be hidden. The extension and re-emergence of critical theory in the form of Deviant Leisure allows a more palatable version. Inevitably women and Deviant Leisure emerge as a topic area.

Hedonic Realism is a critical and prevalent concept in Deviant Leisure. An example explored by Corina Medley applies this notion to her discussion of sites of resistance (Medley, 2019). Medley considers that porn sites intended for lesbian women are sites of resistance which are being subsumed by capitalist forces into a normality of money making. Medley raises questions about the individual choosing to self-harm. An essential question of the thesis is that embedded harms of neo-liberalist capitalism are external harms on the individual, although many more harms are enacted by the individual against themselves. Twisting this, the seventies is examined from both an embedded harm perspective and an internally brought to bear harm against the self. This is contemporaneously and historically observable. Sensitive individuals form a canary-in-the-mine symphony if people are listening. Further this includes suicide and incarceration amongst the mentally ill. Suicide is a scream for help in a cultural chasm.

Deviant Leisure and ultra-realism are different to Marxism yet there is an intermeshing of concepts. A clear definition of the difference between ultra-realism and Deviant Leisure is illusive. Maybe that definition is available because there is a complex relationship between ultra-realism and Marxism. 
Marxism becomes an academic elephant in the room. Deviant Leisure theorists would improve their definitions and analysis if they more frequently situate women into their work or cite more female theorists into Deviant Leisure. The question is are they changing any of the concepts to make them women-usable or assuming that generalizability is embedded into the theoretical discussion.

Raymen and Smith offer a critical analysis employing a cultural and criminological account (Raymen \& Smith, 2019). They extend the theoretical concerns of the ultra-realists to take a theoretical account of risk, transgression in contemporary consumer urban spaces. The built environment is investigated in a future article. These concepts have significant room for new knowledge. The built environment has an impact on mental health and there is a body of work to be investigated there. It is also important to the discussion of the setting of the crime novel because it is Kings Cross and the 'writerly view' is one of setting and 'place'. The concept of place and space are essential to a discussion of the built environment from cultural studies disciplinary angle. The built environment is also a creative interplay between Deviant Leisure studies and the crime novel (Raymen, 2019b). Theorists have examined the night-time economy (Smith, 2014) feminist porn (Medley, 2019) and illicit drug taking (Ayres, 2019). These theorists are looking at contemporary night life. In the 1970s in Sydney Australia, Kings Cross was the doyen of escape from suburbia. Nightly life was highly focused on prostitution, illicit drug taking, illegal gambling, the legal 'alcohol economy' and it was a haven, although perhaps not a safe haven for the LGBTIQ community. This will be explored further in an article on the seventies. It is also form and content of the 1975 crime novel which includes 'dirty cops and dirty politicians' forming tiers of government - fictional - revealing profit from the seedy side of Kings Cross. In effect revealing the capacity of capitalism to cause multiple harms.

The contemporary focus of Raymen and Smith's Deviant Leisure is significant. Their epistemological choice is to go 'big picture' looking for systemic harms focussing on capitalism. Parallel to this, autoethnography is frequently the methodology of choice of Raymen and Smith. In specific journal articles Raymen and Smith log the empirical study of Oliver Smith in 2014 and point to a grounded theoretical approach taken by Winlow and Hall (Winlow \& Hall, 2006). The article 'What's deviance got to do with it? Black Friday sales, violence and hyper-conformity' is a narrowly focused study (Raymen \& Smith, 2015). The nexus of Deviance Leisure is a broad critical analysis brushstroke. They demonstrate currency making Deviant Leisure and the probing of social harm resonant. This article and this research use a reflective aspect. It turns away from the contemporary focus and uses Deviant Leisure as a historical lens. Criminology as a discipline is heavily focused on contemporary society. Combining criminology and historiography to create a theoretical palette is an original and significant contribution to knowledge.

The domain of Deviant Leisure has a gap in the literature, which is gendered. There is some use of the pronoun her and she. The discussion of the 'Night-Time Economy' excludes the topic of prostitution. There is a discussion of mental health at the edges of the work and some evocative language for gambling including 'depressed'. There is a feel for mental health issues. This project potentially makes a significant and original contribution to knowledge in the areas of mental health and possibly prostitution. In writing a novel - a crime novel - which extends the criminological theory of Deviant Leisure and shapeshifting a theoretical paradigm into the creative sphere with an unknown outcome. 
The Deviant Leisure perspective has its home in the ultra-realist reframing of criminology spearheaded by Hall, Winlow and Redhead. Alongside, parallel almost, to the Deviant Leisure theorization, is a significant body of work which prefers the nomenclature 'zemiology'. The relationship between Raymen and Smith's Deviant Leisure and the definition of zemiology is worthy of investigation. Zemiologists are concerned with harm in its multiple variations. The Deviant Leisure work, however, with underpinnings in ultrarealism, depend on the complex interlinking of Lacan and Zizek.

Deviant Leisure enlivens this investigation. The foundation of Deviant Leisure ensues from ultra-realism and parallels ultra-realism in their growth and development as the scholars have strong personal relationships with each other as well as ideas. Within Deviant Leisure each scholar's work is heavily embedded in the others through citations. This strengthens the stream of inquiry. Zizek - and Lacan - are essential to linking from externalised systemic perspective of critical inquiry. The ultra-realists began this process which undergirds their own theoretical position and also substantiates the Deviant Leisure code.

Ayres argues against the infantilization of contemporary adults in her piece of drug taking (Ayres 2019, p. 151). In the 70 s teenagers were expected to be fully functioning adults at 17 or 18 . This involved leaving home regardless of study as a non-income producing choice. This raw experience meant there was no time accorded for infantilization. Rather adulthood at the earliest instance was praxis. Infantilization is a significant feature of mental health plans to almost rebirth the sufferer of mental illness. Two female icons in the northern hemisphere literary canon are Virginia Woolf and Sylvia Plath. In Mrs. Dalloway by Virginia Woolf the character Septimus is armed with the characteristics of the mentally ill, post-WWI. Septimus is treated in a babyish mode when he is hospitalized. This is reminiscent of Woolf's own infantilization when she was hospitalised for a breakdown. She was physically bedbound and forced to consume large quantities of milk. In Sylvia Plath's The Bell Jar the main character is acutely aware of her infantilization. The character considers rebelling but ultimately decides to conform to leave quicker. In the 1940s in Australia adults' teeth were removed as a precaution for electric shock treatment. This further impacts the corporeal nature of stigma (Adair, 2008).

Infantilization is an acutely negative aspect of treatment of both teenagers and the mentally ill. It abrogates the passage of adulthood. It revokes a right to independence and repeals an expectation of growth. The passage of growth is noted in the literary canon in the bildungsroman. A recent example is Wreck and Order by Hannah Tennant-Moore (2016). A woman - the female protagonist - has a tumultuous relationship with her boyfriend. Her behaviour and mindset are exposed by what she allows him to do to her - as cultural expectations of the 2010s is disturbing. This is an example of a common female harm in contemporary society. Infantilization and female self-harm, and societal expectations of women being utilised by men for purposes previously deemed as unacceptable, are congruent with Ayres's viewpoint which broadens and deepens Deviant Leisure theorization.

\section{Individualism}

In an era of 'cool individualism' in which it is culturally imperative to form a unique identity that is distinct from 'the herd', to transgress or cultivate deviant identities is steadfastly conformist (Hall et al., 2008; Hayward and Schuilenburg, 2014; Smith, 2014). Times have changed and in the contemporary context it is the capacity for norms and values to be manipulated by the ideological dominance of consumer 
capitalism that opens up a space for harm to result from the individualistic pursuit of leisure, irrespective of what Bauman refers to as a moral 'duty to the other' (Bauman 2000 in Medley 2019, p. 238).

Raymen and Smith express a critique of capitalist society in 2020, prior to the impact of corona virus. Michael Crotty explores and investigates critical inquiry which underpins Marxist thinking and the relationship we have to society (Crotty, 1998). McGowan examines scholarly thinking such as western Marxism (McGowan, 2002). Deviant Leisure now expands streams of critical inquiry. They do this by funnelling streams of thinking, including critical inquiry and 'western Marxism'. In addition, they link the ultra-realists, and deriving their theorizations parallel to the ultra-realists who significantly employ Lacan and Zizek to come to a position of how do subjectivities arise? Raymen asserts that 'social harm one of the most compelling and challenging concept for the 2020s' (Raymen, 2019a). Tara Brabazon logs that a key reason neo-liberalism has survived since the Global Financial Crises is that intellectual tools have not been appropriate to build an alternative model (Brabazon, 2020, p. 5). Building intellectual tools and models makes a significant contribution to knowledge. Deviant Leisure is an important cornerstone in fresh theorizations of neo-liberalism and concomitant late capitalism. The theory benefits from the inclusion of social harm, normalised, embedded and 'self-harm'. It is in the purview of this article to extend the theorization and add another concept, toxic harm, which includes harm to women and to the mentally ill.

\section{Individualism and Community}

Individualism is a key concept in neo-liberal philosophy. Raymen and Smith argue the detriments of neoliberalism (Raymen 2019a; Raymen 2019b; Raymen \& Smith, 2019). The specific period of the crime novel 1975 - examines the cultural notion of individualism parallel to the development and radicalization of the period of the sixties which underpins that individualism.

In Raymen's' introduction to Deviant Leisure: Criminological Perspective on Leisure and Harm the notion of 'the Good' is examined (Raymen, 2019 in Raymen and Smith eds., 2019). The notion of 'normalised harms' is important. Normalised harms are embedded into neo-liberal capitalism. An example in 1975 in Australia is the unconventional 'dismissal' of Prime Minister Gough Whitlam by the Queens designated representative Sir John Kerr (Hocking, 2012). Recent legal battles have resulted in the releasing of the Palace Letters. This situation exists because Australia is not a Republic rather a member of the Commonwealth. In Australia this is a source of great contestation. It is a centrepiece of the novel set in 1975. This will be addressed by future articles with a historiographical discussion of the seventies and will also investigate the links to individualism.

As opposed to individualism as the primary pathway to reflection on society, Deleuze and Guattari's analysis includes the rhizomatic nature of humanity. Its significance here is as a link to the notion of community (Deleuze \& Guattari [Holland 2013]). Raymen's theoretical evaluation of the nature of society employs the notion of community as an antidote to commodified leisure and embedded harm (Raymen, 2020). The question arises about society's improvement. If it is not engendered through piecemeal policy making. And not through dismantling neo-liberalism because big business has significantly more means - of production, of influencing policing, of affecting subjectivities through advertising. It must come because there is some agreement about the Good. It might also arise through agreement about what is community and how community agitates for inclusion. Inclusion can come to mean more than democracy. 
If inclusion means the excluded being respected. Coming into the fold then, Deleuze and Guattari and the symbolic nature of the rhizomatic plant, may have the roots that sustain, and may make for a more tenable society. When women are genuinely included, then the mentally ill are no longer stigmatised just for existing, breathing. That world where the rhizome is a symbolic and earthy reminder of community may have some antidotes not only to the COVID-19 pandemic of 2020 but to a life based on greed, consumerism, and the deeply embedded harms of neo-liberalist capitalism.

Capitalism and its embedded harms deploy a complex process of control and sublimation which involves 'othering' the mentally ill. This is further codified through Zizek's discussion of Lacan's essential concepts of the Lacanian Real, the Symbolic Order and the Imagined (Zizek, 2000 in Raymen 2019a). This will be developed further in another article on mental health. This is a psychological approach which is strengthened by the sociological approach of Goffman who in the 1960's sought to describe and analyse the processes that result in the stigmatising the mentally ill (Goffman, 1963). Goffman delineates the multifactorial methods that humans use to demonify and discriminate against the 'mentally ill' (Goffman, 1963). A major purpose of the project is to log and consider known and identified stigmatisation and discrimination of the mentally ill and to twist that into a work of fiction - a crime novel - which does not vilify the mentally ill but offers a more accurate and nuanced portrayal by making characters rounded and balanced rather than monocentric in their nature and characterisation. By extension this would allow greater empathy and compassion to the mentally ill. In turn making their burden, their suffering a little lighter. In doing so that process would make a significant contribution to new knowledge.

\section{Mother Shaming: Toxic Harm}

The determinants of mental illness are highly conjectured. RD Laing, an alternative psychiatrist prominent in the 1970s suggests that the parents be held responsible. The complexity of trailblazing white men is not lost on RD Laing's children. Laing was responsible for four sets of children to different women. One child suicided. The damage caused to them by one who seemed so compassionate to the mentally ill is hard not to $\log$ for consideration (Day \& Keely, 2008). The constant blaming of women for the mental health attributes of their children has been debunked by feminists (Mitchell, 1974). Whilst this has been debunked there is a prevalent and embedded philosophy of parents who blame themselves, especially mothers. No doubt mother-shaming has multiple points of entry in neo-liberalist systemic blaming. This affects identity. Shaming and blaming of women and the mentally ill for simply being who they are is toxic. This harm is not only social harm. It corrupts the identity. It is toxic harm.

\section{Ultra-realism and Deviant Leisure}

Deviant Leisure's foundation is anchored in ultra-realist criminology. The ultra-realists utilize Zizek's conceptualisations. Essential to Zizek's approach - which is constructed on Lacanian psychoanalysis to understand the personal - is the concept of subjectivity. This explains the statement by Raymen and Smith that the foundations of 'contemporary liberal capitalism and consumer culture generate harmful and competitive individualistic subjectivities' (Raymen \& Smith 2019, p.19). Unravelling these intricate dependencies is significant and returns to glossaries for assistance in some of the major works. Zizek's theories provide a bridge. They present a current theorization of the broader forces of neo-liberalist capitalism. Zizek's theories are based on Marxist principles but are expressed more through the dynamics of advertising and neo-liberalism than say more time-rendered concepts of class. Classism is used in 
current theoretical discussion but sits alongside racism, colonialism and poverty (Adair, 2008). Winlow and Hall are not afraid to discuss class (Winlow \& Hall, 2013).

However, class is not a key concept in Deviant Leisure. That is where Zizek's modern rephrasing around 'neo-liberalist capitalism' catapults Marxism into a fresh revisioning which is ready for theoretical action in the current complex environment. Raymen questions how we develop a conception of the 'common Good' (Raymen 2019a, p.155). The search for the common good is important. It is an intersection between Deviant Leisure and this project which shines a light on mental health, women and the 1970s. Mentally ill people can be stigmatised and discriminated against. They are like women in their 'otherness'. The neuro-diverse difference connects and interplays with the otherness of women. Deviant Leisure disturbs the notion that neo-liberalism is beneficial and configures questions through social harm. This article confronts this question and extends it further to examine women and social harm and the mentally ill and social harm, within a specific and situated context of the 1970s. The significant contribution to knowledge comes from using a developed theoretical framework, Deviant Leisure, critiqued by feminism and neurodiverse standpoints, then reframed into the contextual lens of the 1970s in Kings Cross Sydney, a unique built environment.

Social harm is essential and inherent to capitalism and greed, not because it is neo-liberalism but because it is capitalism. The same capitalism with new words that existed in 1900 when my grandfather was orphaned into state care for not fitting in. The same capitalism of the crime novel set in 1975 and the same capitalism that expresses a fundamental human need to dominate and control the 'other' there by making itself look and feel good and wealthier than someone else.

Hall, Winlow and Redhead are leaders in the ultra-realist vision (Hall 2019, Winlow 2019 \& Redhead 2019). These theorists unlocked a radical revisioning of the capacities of neo-liberal capitalism to cause harm to the individual. Together with Lacan and Zizek they opened up the grammar of poverty and class. They studied the riots of the working class and football for example. The cornerstone tenets comprise a revamped look at Marxism and its applicability to late capitalism, late modernity, and neo-liberalism. This moment in the development of social harm as a concept is primordial when understanding how feminism can sustain and invigorate first ultra-realism then Deviant Leisure. Multiple classes - working class, poverty class, middle class - need to be consulted about women in late modernity. Their identity is currently tied to consumption of goods, products services, and ideas. Consumerism and advertising have an embedded harm which is nuanced - sometimes not so nuanced - body shaming. Advertising and existing cultural norms collude to make women feel worse and consume more as a result. This exploits the weaknesses of the human condition to benefit a few at the expense of the population of women. A toxic harm.

An example is a song on current children's entertainment television, 'The Wiggles'. Emma, a young woman, in the song as a child 'wears glasses' but all three male performers do a positive activity like play the trombone which enhances their present and future well-being. Emma is being body shamed. Two-year old girls already know, deep in their Symbolic Order (Lacan, 2008 in Raymen 2019a) that they are lesser and valued primarily for their appearance. Women utilize a multiplicity of legal, socially embedded, and sanctioned forms of self-abuse. Alcohol would be but one example. This is how identity formation and women's identity formation in particular, has a maximum focus on the corporeal to the detriment of their 
mental health. Consider the girl who has a genetic predisposition to mental health issues and the embedded harm that neo-liberalist capitalism causes their psyche and their forming identity. This is a combination of body shaming and blatant sexist television. If there are issues of poverty involved for that girl then the smashing of the identity self goes deep. Again, a toxic harm.

Deviant Leisure theorist Thomas Raymen discusses a theory of the Good (Raymen, 2019a). The Good requires an agreement on what is morally reasonable. An attempt to find 'flourishing'. This attempt could be more useful if it did not subsume women into a discussion of 'man', 'human' and allowed and encouraged the feminine to define their own needs and especially their own moral view on what is the Good. Whilst in the short-term this would divide the coalescing views on harm, in the long-term it would strengthen the position by moving away from masculine sources as having a hold on the ontological and epistemological concerns that underpin zemiology.

In 'The Enigma of Social Harm and the Barrier of liberalism: why Zemiology needs a Theory of the Good' Raymen declares 'that social harm is one of the most potentially transformative concepts currently available to the social sciences' (Raymen, 2019a, p. 133). To create change - a one per cent shift toward a society with more common Good than is now visible - something new, or reframed is needed. In a society where capitalism simply replicates itself and reconstitutes all attempts at change (Medley, 2019) then the big issues of social equity, the well-being of the individual and the concomitant issues of systemic and relational abuse continue unabated. There is an inherent push for change, inbuilt into the psyche of some who roam the planet. This includes but is not limited to the organic intellectual (Gramsci [1971] 1999, cited by Brabazon 2020 [podcast]). Like ancient warriors this group want change and look for inroads to change. Another ice age is coming metaphorically. A frozen wasteland of climate change with oil covering birds on my television screen. The screen reminiscent of 1984 (Orwell 1949). The soma of daily medication in Aldous Huxley's Brave New World (Huxley 1932). The sadness of that barely allowed to touch the senses as a working day makes itself known. The great dystopian writers Atwood - The Handmaid's Tale - Orwell, Huxley, seem just a breath away (Atwood [1985]2010). The yellow birds in the mine are singing their song. Will anyone hear?

Central to the concept of Deviant Leisure is its view on deviance. As a concept, deviance has a provocative history in criminology, sociology, youth studies and cultural studies. Social deviance Raymen argues, disguises conformity (Raymen, 2019a). Raymen demonstrates that for example in parkour, the participants believe they are deviating from the norm by participating in something, such as parkour (Raymen, 2019b), or illicit drug taking (Ayres, 2019) or feminist porn sites (Medley 2019), and Contemporary Adulthood and Night-Time Economy (Smith, 2014). The body of work initialised by Thomas Raymen and Oliver Smith emerges on the foundational research of the ultra-realists, Steve Hall, Simon Winlow and Steve Redhead, and has come to agree on certain tenets. An initial agreement is the lack of deviance and the underpinning conformity of the consumer (Raymen, 2019a). The broader scenario is one of contemporary liberalism in their view a 'neo-liberalism' which sits within a framework of neo-liberal capitalism.

Buried within the notion of conformity when it appears to be deviance is a foundational aspect of neoliberalism, one of liberty and individualism. Raymen (2019a) investigates three liberties. Negative liberty which is simply the freedom not to have your rights infringed upon. There is also positive liberty, the capacity to achieve your goals. The third liberty is 'special liberty' used by libertarian financial elites (Hall, 
2012). All the liberties have a need or goal at their foundation, requiring choices. There is an inference that the human being is rational and capable of making choices. The person heads towards 'telos', from the Greek, an endgame, a result. This can be questioned. Raymen looks to Alasdair MacIntyre (1981) a philosopher whose point of entry is one of morality and desire. This makes a marked movement from the perceived rationalism which is Kantian in nature moving towards a desire created morality and decisionmaking basis. MacIntyre provides through 'desire' as primacy, the link which allows the work of Slajov Zizek to question capitalism in its diversity and irrationality. Zizek argues that neo-liberalism is based on an injunction to enjoy life as it creates a desire-based link to neo-capitalism (Zizek, 2000 in Raymen, 2019a; Ayres, 2019; Medley, 2019). The injunction to enjoy derives from the Lacanian discussion of jouissance. The relationship of pleasure and leisure to work and capitalism is earmarked for further discussion.

In effect, there is a binary position developing between theorists where the Good is oppositional to social harm. The definitional relationship is a paradigm which allows zemiologists to conceive of the transformation of capitalism into something more conducive to what used to be the 'left'. The decimation of the left and its many defeats is referred to by many of the authors, notably Steve Hall and Simon Winlow (2013). Social harm is important because it substantiates a link, negative in its association between capitalism and the individual whereas neo-liberalism in capitalism believes and sells itself as positive.

The question of subjectivities is inherent in this discussion. The discussion of neo-liberalism is anthropomorphised in its capacities. Raymen employs the work of Zizek and Lacan to demonstrate a complex relationship with the psychology of the individual and the process neo-liberalism uses to infiltrate the mind and feelings of the individual. It is a complex relationship and any attempts to minimise the complexity result in a theoretical construct which is minimised. This complex relationship to psychology through Lacanian constructs is what previous formulations have been missing when attempting to link complex modern society and other scholarship that might be derived from Marxist concepts. This project is informed by linking Deviant Leisure and its macro and micro-analyses of the human condition, whilst adding a layer of feminism and twisting this to reframe the 1970s. The complex explanation that Deviant Leisure offers is combined with the reframe of feminism and the 1970s offers a significant contribution to knowledge.

Reframing deviant leisure through feminist eyes is essential to the thesis. It also offers innovation in an already innovative theoretical palette. Twenty years ago, Heyes and Meyer note that women were other (Heyes, 2002, Meyers [1999] 2004). In the following twenty-year period not much has changed from a feminist viewpoint. MacIntyre that human beings are subject to desire (MacIntyre, 1981). Further MacIntyre subsumes the female gender into 'human beings' (MacIntyre, 1981). It is possible to look to McIntyre's personal life to evaluate his views. MacIntyre has three women each neatly preceding and following the other as 'wife'. It is illustrative to observe an individual, their external achievements noticing a brilliant philosopher that suits a theoretical persuasion such as Deviant Leisure. Contexts change and behaviours that were unquestioned of men in a previous milieu are revisioned with new social mores and agreements. As women raises their voices particularly prominent is the \#metoo movement of the 2010's. The concern with MacIntyre is both personal and public. This reframing of acceptable behaviour in the male population is as important as any other and establishes a framework on how Deviant Leisure can be sustained and indeed improved by a feminist position. 
The Deviant Leisure approach to subjectivities is based on a Lacanian frame which Zizek has subsumed into his modelling. Raymen uses some critical concepts from Lacan to make the link from Zizek to Lacan to capitalism and back to deviance and conformity. The pirouette here is the agreement that a person has within a 'subjective void' (Raymen, 2019a).

The Symbolic Order, an internal function allows the child to create an identity. An essential tenet here is 'the Big Other' which is a structure which the child places as security in effect structure. Symbolism and the Big Other allow a human being to establish a societal relationship. Raymen acknowledge Zizek's ontology. At the heart of subjectivity is the void, this is also known as the 'Lacanian Real' (Zizek, 2000 in Raymen, 2019a). The being is birthed into a raw state of drives and external stimuli. To make sense of this raw state the child looks for Symbolic Order (Raymen, 2019a, p. 5). This imprint is the social world of symbols, customs, rules, and values. This creates a sense of identity which is calibrated to make sense of life. In the Lacanian Real meaningful subjectivity does not exist. Hall extends this stating that the subject actively solicits Symbolic Order to establish coherence and ontological security (Hall, 2012). Zizek's use of German Idealism and psychoanalysis are fundamental to his ontological propositions. This is challengeable as psychoanalysis is founded on a masculinized white male view of what is constitutive of the Symbolic Order, the Lacanian Real and ultimately 'capitalist realism' (Fischer, 2009 in Raymen 2019a). Women's position as 'other' cannot be obfuscated. It is critical to a whole and balanced theoretical position. A feminised psychoanalytic viewpoint is required to balance these contra-points.

Hall goes deeper and prompts further questioning, detailing what it takes for the subject to be able to make changes in the world order. The question is posed can 'reflection' allow the subject to change that order. Lippens makes the call for a collective reflection and by using the group (Lippens, 2012 in Hall, 2012). Hall contrasts the indeterminacy of birth and the individual against the rigidity of the hegemonic and fixed social order. Dewey's views on higher order thinking include reflection and creativity. Both these thought processes were part of his doxy (Dewey, [1933] 2011). Reflection is critical to change. Reflecting as a group though, may have something to offer this change process.

Additionally, people who are locked into a system of work and a work ethic to match it don't have much time to reflect, or to be creative. As so much of the individual's energy is used to recreate the next week's work. This is demonstrated by the recent pandemic and COVID-19 lockdown. Workers had time available to reflect on Black Lives Matter, and the result was planet-wide demonstration including the dis-figuring and removal of many statues which were acceptable in their context previously but unacceptable in the Great Lockdown reframing. Also, the Great Lockdown of 2020, the precarity of work has been subsumed to the edict 'do not leave your homes'. Work from home. School from home.

This places an enormous burden on teachers in all tiers of learning. In Australia, that teaching cohort is a largely feminised workforce who are more complaint due to social norms which are heavily embedded in societal norms but also in the neo-liberal framework of capitalism. Yes, there have been changes but women immediately step into caring roles because their work is less well-paid owing to centuries of discrimination which takes the form of embedded harm. Hall (2012) rightly delineates the embedded rigidity of hegemonic capitalism in its late stage. Developing Deviant Leisure as a historic lens to reframe the seventies, which is the priority of this article, and future work will demonstrate not only does late capitalism have this characteristic, but that harm and hegemonic rigidity can be symbiotic. 
By contrast Raymen (2019a) and other Deviant Leisure theorists demonstrate exactly how flexible the capitalism system is. As parkour begins it sits outside a capitalism as a resistance, site of rebellion, see also Medley and Ayres for theorization on other sites of resistance, feminist porn and illicit drug taking with similar tropes (Medley, 2019; Ayres, 2019). Parkour begins outside but the highly adaptive and 'systemic nature of capitalism' immediately looks for ways to make money from the existence of parkour. Then there is merchandising, something to sell. The system recreates itself.

Zizek uniquely informs the discussion of the Good life. Raymen notes the Symbolic Order and the Big Other are not real or objective (Raymen 2019, p. 5). Rather they are a collective fiction and shared ideological illusion generated by social and ethical principles which encompasses our imagined vision of the Good life (Zizek 2000 in Raymen 2019, p. 5). For the system to work we must believe it can give us a Good life. And that is a crux in the discussion. Is it giving us a good life? The answer would be no. No. It is Raymen's consideration that the discussion of the Good life is based on ethical deliberations. Continuing, that a revisioning of the Good life is a way to establish and answer to the definition of social harm.

Social harm is a variable, phrase and descriptor that can be known or understood through common sense. If a woman sacrifices herself over and over for others and the result is a deep personal depression. And somehow, she has the tools to observe that process and its outcome then we can see that women and the social norms projected onto them over hundreds of years cause social harm. The Good life for her might be that others take more responsibility. If she uses a process of reflection, and or /of conscientisation as a human and as a woman (Heyes, 2004, Meyers, 2004, Freire [1970] 1993, Hall, 2012, Dewey [1933] 2011) then she might personally choose to devolve the responsibilities to others. However, her role modelling or leadership by example might have a rippling effect into a community. Or she might be ostracized for her differences. Is this another example of toxic harm? Can a woman 'win'? Is winning her deepest desire?

This study summons, acknowledges and then twists this emerging work on Deviant Leisure through a feminist lens and offers a theorization of the seventies. If 'she' sits in group consciousness with other women, they might together come to see the social harm of women's position. Another process of conscientization (Freire [1970] 1993) is education at all its tiers and levels, if women observe other women not being held by traditional roles then there becomes a choice. Returning to Zizek and his Lacanian framework, the collective fiction is disturbed - the ideological illusion is shattered - just a little.

Myriad social harm is embedded in neoliberalist capitalism. Challenging the nomenclature 'neo-liberalist capitalism' affords a credible starting point. This is about not sounding like a Marxist of yesteryear because Marxism has become unfashionable. It has not fended well against feminist critique. It is a masculinized form of software/hardware. The underpinnings of Deviant Leisure make it difficult for Deviant Leisure to enter the mainstream. Reflection is a key concept in creating change (Brookfield [1970] 1993, Dewey [1933] 2011, Hall 2012) either individually, group, or at community level. Sometimes the growth of an idea can be organic. It has no set time and place and will arise as needed by the few who need the idea. Conjecturing further, the ideology of liberty, equality, fraternity that comprised the French revolution were lurking in the wings. Waiting.

This article is shaped as stated previously, as a helical spiral. This is organic and authentic. That is not to be repetitive though it may appear so. It is to include a reflective aspect. The helix weaves and reforms 
like thinking itself. Allowing words to unfold, reframe, revision. That is the intent of the article: to reconsider. The notion of social harm, a study of zemiology leads us to reconsider what is the Good. To identify positions of ethics. First though, the standpoint of Deviant Leisure can be used as a lens, a lens to the past, and a lens to the 'other'. Women as 'other' are not vanished. Nor are women vanquished. The theorization of women and Deviant Leisure is mutually transformative and potentially reframes definitions of social harm and the Good.

\section{References}

Adair, V. (2008). The Missing Story of Ourselves: Poor Women, Power and the Politics of Feminist Representation, 20 (1), NWSA Journal, 1-25, JSTOR, https://www.jstor.org/stable/40071250?seq=1

Atwood, M. [1985] (2010). The handmaid's tale. London: Vintage.

Ayres, T. (2019). Substance use in the Night-Time Economy: Deviant Leisure? Raymen, T \& Smith, O eds. Deviant Leisure: Criminological Perspectives on Leisure and Harm, Palgrave Studies in Crime, Media and Culture, 135-60, accessed 7.7.2020, https://doi.org/10.1007/978-3-03017736-2_7.

Brabazon, T. (2020). 'From bad apples to zombies? Walking dead leadership in the contemporary university', Fast Capitalism, accessed 17.8.2020.

Brabazon, T. (2020). Tara Brabazon's 12 Rules for (academic) life - a stroppy feminist's guide through teaching, lear ... [podcast] Libsyn, 09/12/2020 accessed 13.9.2020, https://directory.libsyn.com/shows/view/id/tarabrabazon

Brabazon, T., Lyndall-Knight, T. \& Hills, N. (2020). The creative PhD: Challenges, opportunities, reflection. Bingley: Emerald.

Brookfield, S. (1995). Becoming a critically reflective teacher. San Francisco: Jossey-Bass.

Curtain, M., \& Sanson, K. eds. (2016). Precarious Creativity: Global Media, Local Labor. University of California Press: Directory of Open Access Books, accessed 24.4.2020,

https://www.doabooks.org/doab?func=search\&uiLanguage $=$ en $\&$ template $=\&$ query $=$ Precarious +Creativity\%3A+Global+Media\%2C+Local+Labor+.

Crotty, M. (1998). The foundations of social research: Meaning and perspective in the research process. Crow's Nest: Allen \& Unwin.

Day, E., \& Keeley, G. (2008). My father, RD Laing: He solved other people's problems - but not his own. Theguardian.com, accessed 21.4.2020, https://www.theguardian.com/books/2008/jun/01/mentalhealth.society.

Dewey, J. [1933] (2011). How we think, Heath \& Co. Boston: Project Gutenberg, http://www.gutenberg.org/files/37423/37423-h/37423-h.htm.

Freire, P. [1970] (2017). Pedagogy of the oppressed. London: Penguin.

Goffman, E. (1963). Stigma. London: Penguin.

Hall, S. (2012). The Solicitation of the Trap: On transcendence and transcendental materialism in advanced consumer capitalism. Human Studies Special issue on Transcendence and Transgression. 35(3), 365-381, Google Scholar, accessed 22.7.2020.

Hall, S., Kuldova, T., \& Horsley, M. eds. (2020). Crime, harm \& consumerism. London: Routledge.

Heyes, C. (2002). 'Identity Politics', Stanford Encyclopedia of Philosophy, Sydney University, accessed 21.7.2020, https://stanford.library.sydney.edu.au/archives/spr2004/entries/identity-politics/.

Hocking, J. (2012). Gough Whitlam: His Time; the Biography, Volume II. Carlton, Vic.: The Miegunyah Press.

Holland. E. (2013). Deleuze and Guattari's a thousand plateaus. London: Bloomsbury Academic.

Kellehear, A. (1993). The unobtrusive researcher: A guide to methods, Chapter 1-2, pp. 1-31. St.

Leonard's, NSW: Allen \& Unwin, accessed 25.3.2020, 
International Journal of Social Sciences \& Educational Studies ISSN 2520-0968 (Online), ISSN 2409-1294 (Print), September 2020, Vol.7, No.3

http://sociologyaustralia.allenandunwin.com.s3-website-ap-southeast-

2.amazonaws.com/files/unobtrus.pdf?fbclid=IwAR3QU7PbtgPH1 foEJvGPFhovb7LeTrDvLI mhzKrxRMYgwq7vmI59oi2S32w

Kotze, J. (2018). 'Criminology vs. Zemiology? Yes, Please! On the Refusal of Choice between False Alternatives', in Boukli, A \& Kotze, J eds., Zemiology: Reconnecting Crime and Social Harm, Critical Criminological Perspectives, pp. 85-106, accessed 21.4.2020, https://link-springercom.ezproxy.flinders.edu.au/book/10.1007\%2F978-3-319-76312-5

MacIntyre, A. (1981). After Virtue: A study in moral theory. London: Duckworth.

McGowan, J. (2002) Democracy's children: Intellectuals and the Rise of Cultural Politics. Ithaca \& London: Cornell University Press. Open Access Creative Commons 4.0, accessed 3.4.2020, https://www.jstor.org/stable/10.7591/j.ctt207g6r2.

Medley, C. (2019). The Business of Resistance: Feminist Pornography and the Limits of Leisure Industries as Sites of Political Resistance, in Raymen, T and Thomas, O eds. Deviant Leisure: Criminological Perspectives on Leisure and Harm, Palgrave Studies in Crime, Media and Culture, pp. 237-57, accessed 15.72020, https://doi.org/10.1007/978-3-030-17736-2_11

Meyers, D. (1999) [2004]. 'Feminist Perspectives on the Self', Stanford Encyclopedia of Philosophy, Sydney University, accessed 21.7.2020, https://stanford.library.sydney.edu.au/archives/spr2004/entries/feminism-self/

Musur, K. (2012). What are the implications of adopting a zemiological framework as an alternative to criminology when analyzing phenomena of global crime justice and security?, Global Crime and Insecurity, accessed 30.4.2020, academia.edu,

https://www.academia.edu/9740337/What_are_the_implications_of_adopting_a_zemiological _framework_as_an_alternative_to_criminology_when_analysing_phenomena_of_global_crim e_justice_and_security.

Orwell, G. (1949). Nineteen eighty-four. London: Secker \& Warburg.

Plath, S. (1963) [2013]. The bell jar. London: Faber \& Faber.

Raymen, T. (2020). Unpublished. 'A Disquieting Suggestion for Criminology', Chapter 1 in The Assumption of Harmless: Revitalizing the Concept of Social Harm.

Raymen, T. (2019a). The enigma of social harm and the barrier of liberalism: Why Zemiology needs a theory of the good. Justice Power and Resistance. 3(1), 133-163, accessed 25.6.2020.

Raymen, T. (2019b). The Paradox of Parkour: Conformity, Resistance and Spatial Exclusion, Deviant Leisure: Criminological Perspectives on Leisure and Harm, Raymen, T \& Smith, O eds., 349377, accessed 10.6.2020, Palgrave Studies in Crime, Media and Culture, https://doi.org/10.1007/978-3-030-17736-2_16.

Raymen, T. (2019c). Lifestyle Gambling in Accelerated Culture, Deviant Leisure: Criminological Perspective on Leisure and Harm, Raymen, T \& Smith, O eds., pp. 259-282, Palgrave: Palgrave Studies in Crime, Media and Culture.

Raymen, T. (2018). Parkour, deviance and leisure in the late capitalist society. Emerald, Emerald Studies in Deviant Leisure.

Raymen, T., \& Smith, O. (2020). Gambling and harm in 24/7 Capitalism: Reflections from the postdisciplinary present', in Crime, Harm and Consumerism, Hall, S. Kuldova, T. \& Horsley, M. eds., London: Routledge, 123-139.

Raymen, T., \& Smith, O. eds. (2019). Deviant leisure: Criminological perspectives on leisure and harm. Palgrave, Palgrave Studies in Crime, Media \& Culture.

Raymen, T. \& Smith, O. (2019). The Deviant Leisure Perspective: A theoretical introduction' in Raymen, T. \& Smith O. (2019) eds. Deviant Leisure: Criminological Perspectives on Leisure and Harm, Palgrave Studies in Crime, Media and Culture, Palgrave Macmillan, Chapter 2, 17-44, accessed 15.3.2020, e-book https://link-springercom.ezproxy.flinders.edu.au/content/pdf/10.1007\%2F978-3-030-17736-2.pdf 
Raymen, T. \& Smith, O. (2019) Deviant leisure: A critical criminological perspective for the twenty-first century. Critical Criminology. 27(1), 115-130.

Redhead, S. (2019). Real ultras and ultra-realism: Deviant leisure cultures, high theory and raw realism, in Raymen, T \& Smith O, 2019, eds. Deviant Leisure: Criminological Perspectives on Leisure and Harm, Palgrave Studies in Crime, Media and Culture, Palgrave Macmillan, Chapter 2, 87-102, accessed 15.3.2020, e-book https://link-springercom.ezproxy.flinders.edu.au/content/pdf/10.1007\%2F978-3-030-17736-2.pdf

Smith, O., \& Raymen, T. (2018). Deviant Leisure: A criminological perspective, Theoretical Criminology, 22(1), 63-82.

Raymen, T. \& Smith, O. eds. (2019). Deviant Leisure: Criminological perspectives on leisure and harm, Palgrave (Palgrave Studies in Crime, Media \& Culture).

Raymen, T. \& Smith, O. (2019). The Deviant Leisure Perspective: A theoretical introduction' in Raymen, T \& Smith O, 2019, eds. Deviant Leisure: Criminological perspectives on leisure and harm, Palgrave Studies in Crime, Media and Culture, Palgrave Macmillan, Chapter 2, pp. 17-44, accessed 15.3.2020, e-book https://link-springercom.ezproxy.flinders.edu.au/content/pdf/10.1007\%2F978-3-030-17736-2.pdf

Raymen, T. (2019c). Lifestyle Gambling in Accelerated Culture', Deviant Leisure: Criminological Perspective on Leisure and Harm, Raymen, T. \& Smith, O. eds., Palgrave, 259-282, (Palgrave Studies in Crime, Media and Culture).

Smith, O. (2014). Contemporary adulthood and the night-time economy. London: Springer.

Tennant-Moore, H. (2016). Wreck and order. London, New York: Hogarth.

Winlow, S. (2019). What lies beneath? Some notes on ultra-realism, and the intellectual foundations of the "Deviant Leisure" Perspective, in Raymen, T. \& Smith O. (2019). eds. Deviant Leisure: criminological perspectives on leisure and harm, Palgrave Studies in Crime, Media and Culture, Palgrave Macmillan, Chapter 3, pp. 45-65, accessed 15.3.2020, e-book, https://linkspringer-com.ezproxy.flinders.edu.au/content/pdf/10.1007\%2F978-3-030-17736-2.pdf

Winlow, S. \& Hall, S. (2013) Rethinking social exclusion: The end of the social? London: Sage. Woolf, V [1923] (1992). Mrs. Dalloway, Penguin, London. 